\title{
Libraries and librarians: Key partners for progress in health literacy research and practice
}

\author{
Wanda Whitney*, Alla Keselman and Betsy Humphreys \\ National Library of Medicine, National Institutes of Health, Bethesda, MD, USA
}

\begin{abstract}
The field of librarianship has a history of involvement in patient education, general literacy and information literacy efforts. This history and prominent placement in communities make libraries and librarians an excellent resource in advancing health literacy practice and research. This chapter provides an overview of health literacy and health information literacy efforts in U.S. libraries over the past two decades.

The chapter begins with the description of the role of the U.S. National Library of Medicine in developing resources, programs, and partnerships serving health information needs of the public. It then overviews special training programs for increasing librarians' expertise with health information and health literacy support. The narrative also presents different models of health information outreach programs in diverse communities, focusing on serving special populations that may suffer from health disparities.

The second half of the chapter describes libraries' and librarians' health information response to continuously evolving contexts, mediums, and requirements. One subsection describes librarians' outreach effort with cutting-edge technologies, such as virtual worlds and gaming. Another focuses on supporting patients' information needs in clinical settings. Two more describe how libraries meet patrons' health information needs in the context of disaster preparedness and health insurance market place sign-up.

While presenting the information, to the extent possible, the chapter draws upon research and evaluation of the effectiveness of different types of programs. It also discusses enablers of successes, limitations of the existing data, and directions for future research.
\end{abstract}

Keywords: Health information literacy, health literacy, patient education, libraries, health information outreach

\section{Introduction}

Libraries and librarians are excellent resources for advancing research and practice in health literacy. They are nearly ubiquitous, generally perceived as trustworthy and helpful, and collectively experienced in general health and patient education. Different types of libraries, e.g., public, hospital, academic health center, have different strengths to bring to health literacy interventions. Programs that involve multiple types of libraries may have a better chance of being sustainable and successful.

Two-thirds of the population of the United States live near a public library [24]. Many also have access to physical libraries in schools, community centers, colleges or universities, health care institutions, and places of employment. High quality digital libraries are available to anyone with access to a web-capable device and an Internet connection. This includes anyone who is willing and able to visit a public library, as well as the many millions who have their own devices and Internet access.

\footnotetext{
${ }^{*}$ Corresponding author. E-mail: whitneyw@mail.nlm.nih.gov.
} 
Relying on libraries to identify, organize, and provide easy public access to high quality, understandable health information can make health literacy interventions more scalable and sustainable. For individuals who are self-motivated to improve their understanding of health topics, organized libraries of high quality health information, whether digital or physical, greatly simplify the search for relevant information.

Long before "health literacy" became a named topic of interest or the Web browser was invented, libraries and librarians of various types were engaged in patient education and in providing health information written for consumers or the general public, often in cooperation with other organizations and institutions [56]. For more than a century, public libraries and librarians have also been deeply involved in programs to advance general literacy in children and adults, sometimes using easy-to-read health information as source material.

In the 1990s, however, an increasing focus on health literacy as a concept and as an area of research and practice, the spread of the Internet and the World Wide Web, concern about the "Wild West" of electronic health information, and the doubling of the National Institutes of Health (NIH) budget came together in ways that greatly expanded the involvement of U.S. libraries in health information literacy and health literacy activities. This chapter describes the role of the U.S. National Library of Medicine (NLM), a component of NIH, in initiating this expansion; efforts to prepare librarians to assist the public in obtaining high quality health information; and the roles librarians play in health information outreach, use of innovative technologies, providing health insurance information, health literacy interventions in clinical settings, and access to information in disasters and emergencies. The chapter concludes with thoughts about the important contributions libraries and librarians can make to health literacy research and practice.

\section{The role of the U.S. National Library of Medicine}

The NLM, the world's largest medical library, builds and provides electronic information resources used billions of times each year by millions of scientists, health professionals, and members of the public around the world. Through its information systems, an informatics research portfolio, extensive training programs, and many partnerships, the NLM plays an essential role in catalyzing and supporting the translation of basic science into new treatments, new products, improved practice, useful decision support for health professionals and patients, and effective disaster and emergency preparedness and response. The NLM coordinates a 6500 member National Network of Libraries of Medicine (NN/LM) that provides a field force for improving access to high quality health information in communities across the U.S., with an emphasis on populations with health disparities.

Prior to 1997, the NLM's involvement with health literacy was restricted to acquiring, describing, and providing access to pertinent research literature, as well as funding some relevant research and resource development projects. NLM also provided a few free databases and outreach programs designed for patients and the general public in specialized areas, such as HIV/AIDS, for which targeted funding was available.

In 1997, the NLM was able to eliminate fees for searching MEDLINE, a database of indexed citations and abstracts from biomedical journals, and its other databases due to the expansion of the Internet and the World Wide Web. As users obtained their own Internet connections, they no longer needed commercial telecommunications services to reach NLM databases, and the Library no longer needed to charge users their fair share of a large central telecommunications bill. When NLM's MEDLINE became 
freely searchable via the relatively simple PubMed Web interface, use skyrocketed. The general public became a major user group, although MEDLINE did not provide the basic explanations of health and disease topics that many of them were seeking [39].

The Web provided a cost-effective platform for NLM to deliver health information services to the public, and the doubling of the NIH budget gave NLM the additional funding necessary to develop new services targeted toward the general population. In this propitious environment, the NLM Board of Regents revised a previous policy against development of services for patients and the public that had been dictated by budget limitations. In 1999, the NLM Board stated that the Library should “... improve the national infrastructure that supports the public's access to electronic health information... so that all people in the U.S. have a known, accessible, understandable, and affordable source of current, authoritative health information" [45]. In 1998, the NLM had released the MedlinePlus consumer health information website [44], the first of an array of new services for the general public. The Library also expanded its outreach programs, previously directed primarily to underserved health professionals, to involve public libraries and other community-based organizations, often in partnership with the NN/LM, in improving the public's awareness of, and access to, health information services in minority, rural, frontier, inner city and other underserved communities $[12,22,68]$.

In this same period, the NLM examined published evidence on health communication and health literacy to identify best practices applicable to consumer health information services. Scott Ratzan, editor of the Journal of Health Communication, and Ruth Parker, a pioneering health literacy researcher and advocate, were engaged to assist NLM staff in compiling an initial bibliography "... to help define and describe the evidence base for advancing health literacy programs by examining theories, strategies, and tactics in the published literature" [54]. Released in early 2000, the bibliography contained a novel definition of health literacy, "the degree to which individuals have the capacity to obtain, process, and understand basic health information and services needed to make appropriate health decisions" [52]. As of 1999, there was limited evidence about which learning strategies and tactics were most viable. However, the new definition of health literacy was widely cited and adopted by the Institute of Medicine [31], and the bibliography provided a foundation for further research.

Since 2000, the NLM has continued to expand and enhance its suite of information services and outreach programs designed to provide patients, families, and the general public with easy access to high quality health information where and when needed. The development of trusted information services that promote health literacy was identified as a major goal in the NLM Long Range Plan for 2006-2016 [46]. NLM staff members have been active participants in the programs of the Roundtable on Health Literacy, initially of the Institute of Medicine, and now of the National Academies. The Library's heavily used services for the general public now include extensive information in Spanish, as well as resources in more than 40 other languages; spoken, interactive, and "easy to read" information; websites designed to display effectively on devices of all sizes, including smartphones; application programming interfaces (APIs) so that access to patient education information can be embedded in external information systems, including electronic health records (EHRs) and patient portals; K-12 educational materials; and the NIH MedlinePlus magazine, in English and Spanish, produced in cooperation with the Friends of the National Library of Medicine and other NIH Institutes and Centers. By providing enhanced, integrated access to electronic consumer health and patient information produced by authoritative sources, NLM has facilitated Web discovery of high quality information written for the general public, both for those seeking information for themselves and those seeking materials for use in health literacy research and interventions. 
In addition to expanding the universe of credible, readily available health information written for the public, the NLM has been a very significant supporter of health information outreach projects and initiatives via the NN/LM, which now incorporates many public libraries and community information centers as well as hospital and academic health sciences libraries, and in partnerships with minority serving institutions, public health departments, schools, churches, and other community-based organizations. Through the NN/LM and in cooperation with the Medical Library Association (MLA), the NLM has developed training programs and materials to assist librarians and information specialists in providing consumer health information services and designing and evaluating health information interventions [14]. In addition to the health literacy activities involving libraries that are discussed in this chapter, NLM has also supported and conducted a wide range of related research and development, including informatics research on personal health records, integration of patient education information in EHRs, and consumer health language.

Projects supported by the NLM have produced a substantial portion of the published evidence about health literacy research and practice involving libraries and librarians that is discussed in the next sections of this chapter.

\section{Preparing librarians to assist the public in obtaining high quality health information}

In 1998-1999, with assistance from the Friends of the National Library of Medicine and the Kellogg Foundation, the NLM and the NN/LM undertook a pilot program involving 41 public libraries or library systems (more than 200 facilities) in nine states and the District of Columbia. The objectives were to learn about the current role of public libraries in providing health information and to determine how NLM and its network might help public libraries enhance the public's access to health information. Each public library received a grant to provide computers, Internet access, or health information materials to their patrons and was partnered with a NN/LM network library which provided staff training, including in the use of MedlinePlus and other NLM information services, and advice about handling health questions. The results of the evaluation component of this project revealed that few public libraries had health information centers, but that health information ranked among the top 5 or 10 topics of interest to their patrons. Many of the public librarians involved in the pilot were inexperienced, and therefore uncomfortable, in providing health reference assistance to patrons. The training provided to an estimated 1150 library staff and volunteers was therefore enthusiastically received and highly valued. The pilot project did not generate significant numbers of public library requests for documents from medical libraries, as some had expected [67].

Following up on this pilot, NLM increased funding for the NN/LM to support work to improve the public's access to health information. In 2000, NLM and the Regional Medical Libraries in the NN/LM set a goal to ensure that by 2005 every public library in the nation would be aware of NLM's free Webbased information resources and able to provide access to them. In addition to supporting individual projects involving public librarians in specific locations [58,64], the Regional Medical Libraries collaborated on the development of a consumer health information course available to public librarians across the country. The training modules they developed provided the basis for the MLA Consumer Health Information Specialization, which "offers basic and advanced training opportunities for individuals whose work roles demand they provide information services to the public, patients, and families" [1].

Later, in 2008, MLA sponsored a two-day Health Information Literacy Research Project conference. "Health information literacy" is a form of "information literacy" [2], defined as the ability to find and 
assess the relevance, validity, and utility of information for a particular purpose. Librarians in academic settings have long provided formal and informal instruction in information literacy. For health sciences librarians, this has often involved teaching students and practitioners of medicine and other health professions to search online databases and to evaluate the quality of the clinical research evidence in journal articles [60]. Health information literacy is a prerequisite for effective selection of health information for any purpose, whether it be a library service or a health literacy intervention or a family medical question. Health information literacy may be viewed as a component of health literacy pertaining to the ability to obtain health information. However, unlike health literacy, it is not essential for understanding and making use of pre-selected health information, such as signs in health facilities, written instructions provided by health professionals, or web services organized by health literate librarians. The 2008 MLA conference led to the development of a health information literacy toolkit with resources such as health literacy curricula. Librarians and others wishing to provide training can adapt the curricula to their individual communities [43]. MLA also published the Medical Library Association Guide to Health Literacy in 2008 with the goal of helping librarians to "... be better able to understand the issues that comprise health literacy, learning how to help others become health literate, and how to become change agents within their organizations" [34].

Other health information training opportunities targeted toward public librarians include those offered by the American Library Association's (ALA) and WebJunction, a division of OCLC Research. Last offered in 2015, the ALA's six-week Health Information 101 web-based course includes an introduction to the concepts of health literacy and provides guidance for providing health information to low literacy populations [8]. WebJunction offers online training and hour-long webinars on consumer health topics for librarians, as part of a series called Health Happens in Libraries, with topics such as: Health Information Resources for Library Staff, Public Health and Public Libraries: Librarians as Health Literacy First Responders, and Public and Health Sciences Library Collaboration for Community Impact [3]. These and other training resources developed for librarians can be very useful to others, including anyone interested in identifying materials appropriate for health literacy interventions or research.

The last decade has definitely seen an increase in the number of librarians who have received specific training in meeting health information needs of the public and in health literacy concepts. Of course, this does not mean that all public libraries are equally well-equipped to help those seeking understandable health information or that all library workers in a given library have relevant knowledge and training [56].

\section{Librarians and health information outreach}

The capabilities of public and medical libraries to provide consumer health information have increased as a response to consumer demand and the availability of consumer health information training [25]. Librarians field consumer questions at the information desk, taking advantage of a number of credible information resources freely available on the Internet, pamphlets and other print materials from local public health agencies, or through subscriptions to medical databases or journals. Libraries hold health fairs and other community events, inviting other community organizations with additional health information expertise to participate [20]. Here, we explore the various ways that libraries provide health information outreach, specifically through train-the-trainer models, to general and special populations, such as ethnic minorities, older adults, and children.

Although librarians in different settings are prepared to provide health information outreach within their own facilities, this model may not be the most desirable or efficacious method for populations with 
special needs and concerns [23]. Health literacy advocates call for more participatory methods, especially when providing outreach to diverse populations, such as communities of color, older adults, and teens. Community involvement in train-the-trainer health information programs helps libraries overcome neighborhood suspicions about the remote management of health related programs and interventions [23]. Libraries now are more likely to implement health information outreach programs that employ variations of the train-the-trainer approach by partnering with community-based organizations.

There are important advantages to train-the-trainer models of outreach. Firstly, training community members increases libraries' reach exponentially as community members teach their peers who then go on to teach others. This method also has the potential to empower disenfranchised communities since health information is provided by the community for the community. Lastly, community train-the-trainer models can be adapted to fit the community being targeted based on its particular characteristics and needs. Such targeting aligns with recognition, by the NLM and many other organizations, of the need to provide health information outreach to underserved populations and communities [46].

Successful models of community engagement take on different forms. Some successful train-thetrainer programs have focused on intergenerational training. For example, in one intergenerational program, librarians demonstrated health information resources to university students in a six-month period so they could, in turn, help older adults use the Internet to locate health information [29]. There are also successful examples of peer-to-peer training. Librarians at the University of Texas Health Science Center at San Antonio worked with high school librarians to teach teens about MedlinePlus and MedlinePlus en español so that they could share that information with their friends and, later, with the broader community [63]. These peer tutors not only learned about health information, they also received training in recognizing personal situations that would require librarian support or intervention. Tutors gave presentations that increased their reach to 350 students and teachers in their school and the surrounding counties, as well as parents and other family members. The program was so successful that it expanded to other schools in the district and still continues today [48].

In another program along the Texas border region, medical librarians from the University of Texas Health Science Center at San Antonio partnered with the Texas A\&M University Center for Housing and Urban Development (TAM-CHUD) to train lay community health workers, known as "promotores" in Spanish, to find consumer health information for fellow residents using MedlinePlus and MedlinePlus en español [49]. Fifteen "promotoras" provided weekly examples of how they had used health information found on MedlinePlus to learn more about a condition, make better decisions about treatment, or commit to healthier behavior. In evaluating the project, investigators determined that training the "promotoras" to use MedlinePlus resulted in increased usage of this resource within the community [49]. Although lost funding contributed to the end of this program in several community centers, the investigators found that the program had promise and could be adapted for health information outreach for any population.

Whatever approach to health information provision librarians choose, they need to keep in mind important considerations that, if unheeded, may hinder the success of such programs when working with diverse community populations. Many times a great need exists to teach basic computer and information literacy skills, especially among older adults; so many programs offer these services as well. For example, Strong, Guillot, and Badeau [59] describe the Senior CHAT project in Louisiana that taught older adults basic computer skills so that they could then move on to Internet skills that would allow them to search for health information using NIHSeniorHealth and MedlinePlus. In another example, Xie and Bugg [70], partnered with multiple agencies and public libraries to provide computer and information literacy training to senior adults so they could navigate the same sites for authoritative consumer health information. Choosing public libraries to deliver the training, they hypothesized that older adults would 
experience less anxiety and increased computer interest and efficacy after participating in the training. Chu et al. [16] completed a similar project with low-income older adults enrolled in a meal program in their local YWCA with seniors reporting higher confidence and self-efficacy using computers to search the Internet for health information. Overall, evaluations of programs with older adults, such as the ones described here, show that they continue to use the consumer health web sites to learn more about their conditions and help them make better-informed health decisions. Some participants report these changes several weeks after the program has ended [59].

Other project developers focus on elementary or middle school-aged children who have unique needs and concerns that call for programs adapted to their reading level, attention span, and overall developmental readiness. For example, in Caddo Parish, Louisiana, librarians sought to use story time to teach children about healthy living [69]. They also created a Web portal and other educational materials to provide children with access to up-to-date authoritative health information. Because of the relatively large increase in overweight and obese children in the state, librarians chose to focus on encouraging young children to adopt an active lifestyle. Resources also included materials related to nutrition and basic hygiene. While the project sponsors didn't complete a formal evaluation of the project, they noted that nearly 800 students took part in the health-themed story hours; and the project developers received additional funding to develop new activities and reach out to more libraries requesting to participate in the project [69].

In summary, published literature suggests that successful health information outreach by librarians can take many different forms. Train-the-trainer models can be particularly effective in providing health information outreach to special populations that may suffer from health disparities and that require different approaches to satisfy different health information needs. These target populations include minority communities, such as African Americans and Hispanics. The information projects mentioned above and other research studies have shown that introducing people to new information resources works best when the providers are similar to them [23] and when special needs are considered and planned for from the beginning.

\section{Using innovative technologies}

Libraries have led the way in providing health information training and outreach via traditional approaches described above. In addition, they also have broken new ground in providing outreach via different media such as virtual worlds and gaming. These approaches, often first applied in programs for health professionals, proved adaptable to serving the public. For example, in 2006-2008, NLM funded the development of HealthInfo Island in a 3D virtual world, Second Life, managed by librarians and health professionals. Resources and programs for the island were developed in partnership with library systems in Illinois and the Netherlands [11]. Presenting health information in a virtual world draws upon an existing popular culture, encourages innovative information visualization, and may reduce accessibility barriers for people with chronic illnesses or disabilities who may be homebound. HealthInfo Island hosted a medical library and a consumer health library that linked visitors to quality interactive health and wellness information. It was also the site of "Health Information Research Lab" created by NLM that piloted providing quality consumer health information through podcasts, automated tours, and chatbots [11]. Providing individualized support, volunteer consumer health librarians developed personalized reading lists that addressed visitors' queries [4]. Maintenance and sustainability of virtual reality sites present a unique challenge. In part, this is due to high cost and the fact that the virtual reality environment (in this case, Second Life) is owned by an independent company with its changing rules, policies, 
and priorities. While we don't know how viable HealthInfo Island, now owned by Virtual Ability, Inc., will be in future years, it does offer a creative way to access consumer health information.

Another innovative technology often used in education and training alongside virtual world simulations is gaming. One gaming employment approach is the serious games movement, which promotes the development of games with other-than-entertainment primary objectives. Serious games have been used in a number of fields, including education, emergency management, and healthcare. While published literature provides no examples of libraries using serious games in consumer health information programming, they have discovered that gaming devices such as the Wii may provide a creative way to connect the general public with authoritative health information. For example, NLM also funded a project entitled One, Two, Wii: Get Fit and Health Savvy @ Your Library [17]. The project investigators partnered with school and public libraries to offer the game consoles for the public during health fairs, meetings, or other events where library staff would also introduce them to health information resources such as MedlinePlus [17]. The success of this project led to additional NLM funding for a second project, Engage Your Health Information Seekers: Wii Health Information Resources Kit. The kit offers libraries two Wii systems and games with a manual of suggestions for health fairs or other wellness events and resources for quality health information [17]. Project leaders find that both projects have increased awareness of the outreach assistance provided by the medical library, as well as health information resources from NLM.

Libraries differ with respect to the sophistication of the technology available to them. Similarly, patrons differ in their interest and comfort level when it comes to technologies like virtual worlds and gaming. More information is needed to establish best practices of employing cutting-edge technologies in libraries. It is clear, however, that many librarians have the interest and skills needed for adapting creative technologies for health information outreach.

\section{Libraries, health literacy, and the U.S. Patient Protection and Affordable Care Act}

U.S. libraries and librarians serve the public's information needs with regard to health insurance enrollment in the context of state and federal law and regulation, currently including the Patient Protection and Affordable Care Act (ACA). In most cases, libraries respond to the public's health information needs with approaches and resources that have evolved gradually. However, there are also times when the field has to react to a time-sensitive emergent need. For example, on June 30, 2013, in a special message to ALA conference attendees, President Barack Obama called on libraries to support the public's information needs concerning ACA. The effort was to commence during health insurance market place sign-up, scheduled to open on October 1 of that year. Asking libraries to provide such guidance placed the needed support within an easy reach of potential enrollees. The ACA provides health insurance access to populations often characterized by lower health literacy and reduced access to information technology. These populations also often have less advanced computer skills, and libraries are places that traditionally provide computer access and support to the disadvantaged. Involving libraries also built upon their support of other government services, such as information provision on the topics of income tax, citizenship, patents, and disaster relief [41]. Studies of health insurance literacy provide additional evidence in favor of engaging librarians in ACA information support. These studies suggest that most health insurance materials place too-high numeracy and literacy demands on the enrollees $[50,61]$. The complexity deters individuals from health insurance enrollment, while providing sign-up support increases enrollment [61]. At the same time, political controversy around the ACA, complexity of the information, and short timeframe posed challenges for libraries and librarians. 
As a professional field, librarianship had an established professional development model, used by the NLM, NN/LM, and major national organizations to provide resources and training for local libraries. In response to the President's call, ALA hosted a number of events during its 2013 annual conference to address ACA support preparedness. Following the conference, ALA formed a partnership with several organizations, including NN/LM and WebJunction, in order to prepare public libraries for the task [19]. NN/LM regional libraries (e.g., the Mid-Atlantic NN/LM Region) offered webinars and built websites to support public librarians in their efforts. WebJunction offered training workshops through its Health Happens in Libraries program. At the request of NN/LM consumer health coordinators, NLM's MedlinePlus Health Insurance page became a central repository of updated ACA information from NLM and NN/LM.

Despite organizational effort at all levels, pre-rollout anxiety remained [19]. Many public librarians did not know what to expect. Their uncertainty spanned many areas, from the anticipated amount of visitors with ACA queries to the likely nature of those queries. Public librarians had to learn about ACA, as well as allocate staff time and arrange computer space in order to provide support. Due to the novelty of the situation, NN/LM, ALA, and WebJunction could not always provide the information needed, nor could they reach every single public library in the country with the information. According to one informal study, only $57 \%$ of the 88 survey responders in Massachusetts reported having received ACA information links and training prior to the ACA sign-up [41].

As ACA information provision to the public takes place in the trenches of public libraries, not much published information exists about the preparedness and reaction of first responders, as well as about the process itself. At this time, our insight has to come from small-scale informal surveys and case studies. For example, Kara Kohn [35] informally surveyed "82 libraries" in Illinois and Margot Malachowski [41] surveyed 88 Massachusetts librarians about their experience with ACA information provision. Both surveys are reported in a format that makes assessing representativeness of their sampling impossible; and the authors, both librarians, readily acknowledge the tentative (in Kohn's words, "(very) quick and dirty") nature of their data.

According to both sources, very few librarians (e.g., 5\% of those surveyed by Kohn [35]) felt that libraries should not be involved in ACA information provision in any capacity. What varied was the desired and anticipated level of involvement. At a minimum, libraries felt it was their duty to provide Internet access to online forms or help enrollees with print forms and refer patrons to additional resources $[35,41]$. Some felt uncomfortable with providing more, out of a concern for appearing biased in regard to a controversial political issue, as well as because of the challenging nature of the information. Others, however, conducted workshops and trainings, partnered with navigators and certified counselors from outside organizations, invited speakers, and created web pages with local ACA information resources on their websites [6,19,41]. For example, Waukegan Public Library became a 2013 IMLS National Medal Winner for its effort in supporting ACA rollout in in Lake County, IL. The library reached this mark by providing extensive training to its staff and offering bilingual signup support sessions. Building upon this success, Waukegan library also continued conducting its bilingual health literacy skills classes past the rollout period [5].

The Waukegan library experience provides a small-scale example of how information support of a specific need can stimulate larger health literacy support efforts. The opportunity was also noticed by the ALA. In 2015, ALA published Libraries and the Affordable Care Act: Helping the community understand health-care options. As a professional development resource, the book helps librarians understand the basics of the ACA and provide support to enrollees. In addition, it calls upon librarians to use the 
process for "engaging adults in the expansion of their functional understanding of health literacy and financial literacy as they relate to both insurance and healthy living" [27].

The emergent story of ACA information support in libraries exemplifies the potential and the challenge of libraries' response to a novel, fast-developing issue. A number of questions need to be answered in order to evaluate the response. The field needs detailed data about the nature of the public's information needs in the context of ACA; librarians' readiness to support them, including specific challenges and concerns; and actual utilization of libraries for ACA information inquiries. Fitting the three pieces of information together will bring into focus the current state of affairs and highlight future directions. To obtain data about public librarians' preparedness and practices in support of ACA, NLM is currently conducting a nationwide survey of library workers in 20 states, ten with a federal health insurance exchange and ten with state-run health insurance exchanges, in collaboration with the School of Library and Information Studies at University of Wisconsin, Madison [9]. At the present, it is clear that the complexity of ACA information underscores the need for improving American public's health literacy [30], an endeavor in which libraries will continue playing a significant role.

\section{Librarians' role in health literacy support in the clinical setting}

Librarians also support patients' health literacy and health information needs in clinical settings. Librarians can be effective leaders or participants in efforts to make health care organizations "health literate" [13]. In outpatient and inpatient clinical settings, however, their contribution to promoting health literacy most frequently occurs via their support of information prescription initiatives. Information prescription programs, often denoted as Information Rx, involve physicians supplying patients with "prescriptions" for quality evidence-based health information that is specifically selected to address the patient's condition. Prescribed materials may also be tailored to match the patient's other characteristics, such as preferred learning style and reading level [36,37]. These programs are more targeted to the general patient education or consumer health information services.

Librarians participate in information prescription initiatives in two ways. In one model, librarians educate clinicians about quality patient education resources. Many such efforts involve promoting the NLM MedlinePlus consumer health information portal and "Information prescription toolkit" that makes use of it. The toolkit is a box that contains several information prescription pads and some promotional materials featuring MedlinePlus. A large-scale example of such initiative is the Information Prescription Program, spearheaded by NLM in 2004 in collaboration with the NIH and the American College of Physicians and implemented and evaluated in a number of institutions [32,33].

Another model involves librarians filling the prescription by selecting and packaging information materials for each individual patient. For example, Eskind Biomedical Library at Vanderbilt University Medical Center developed Patient Informatics Consult Services (PICS) dedicated to filling information prescriptions [66]. Eskind librarians created an "information prescription" referral form for clinicians to use with their patients. After clinicians complete the form, noting, in addition to the topic, any special factors that need to be considered, patients take it to the patient section of the library to fill. There, librarians put together a packet of targeted authoritative information and discuss quality information evaluation criteria with the patient. They also send a copy of the packet to the referring clinician. In addition to implementing PICS, librarians at Eskind also demonstrated feasibility of tailoring presentation of prescription materials to patients' learning style preferences, although the impact of this tailoring on patients' satisfaction and learning was mixed [36,37]. 
Another example of successful information prescription implementation is at the University of Medicine and Dentistry of New Jersey (UMDNJ) university hospital [15]. There, nurses send information prescriptions for inpatients to the school's Cooper Library via the hospital's clinical information system, indicating desired readability level of the materials. Librarians respond by using patient transport to deliver two copies of the information packet (for the patient and for the chart) to the nursing station. In yet another successful hospital implementation example, health sciences librarians at Englewood Hospital and Medical Center make rounds of clinical floors, asking nurses whether any of their patients need patient education information. Frequently, nurses either request specific information, or direct librarians to speak with patients about their information needs [40].

While librarians working with information prescription programs do not always come into direct contact with patients, such interactions have the added benefit of teaching patients to recognize health information quality criteria and navigating specific websites [21,66]. Going beyond this, Leisey [38] describes a unique project that involved an NLM-funded social work information specialist position at Virginia Commonwealth University Library. The goal of the project was to help cancer patients understand their condition and the healthcare system, manage information from multiple sources, and deal with emotional issues. Social work information specialists approached patients at VCU Massey Cancer Center offering on-site sessions that provided information and basic counseling. Some participants also received projecttailored notebooks that helped them record and organize information about their providers, treatment, appointments, labs, medications, and expenses.

Several potential enablers of information prescription success stand out in the literature. One is a close collaborative connection between the library and the clinical setting that it supports. For example, at the time of its highly successful information prescription implementation, the director of the UMDNJ Cooper Library was a member of Cooper University Hospital Patient Education Committee that included clinicians and hospital administrators. At UMDNJ, the impetus for the effort came from the top because a visit from the Joint Commission on the Accreditation of Health Care Organizations (JCAHO) recommended improving documentation of patient education activities in patients' charts. In contrast, at Englewood the initiative came from the library and its collaboration with the patient education oriented Meland Foundation. There, librarians' proactive visits to clinical floors to offer their services greatly improved nurses' utilization of the library for patient education [40]. As mentioned in an earlier example, integrating information prescription with electronic hospital records is another powerful way to embed the connection between the clinic and the library into the clinic's work flow [15].

Most research into the impact of information prescription programs focuses on clinician and patient satisfaction as outcome variables, often finding increase in satisfaction in both groups [42]. There is evidence that patients who receive information prescriptions are likely to fill them and develop positive attitudes towards the resources they promote [10]. These patients also intend to continue using prescribed resources in the future [18]. Siegel et al. [55] and D'Allesandro et al. [21] also found that information prescription initiatives decrease patients' visits to poor quality sites and increase utilization of the prescribed sites. Information prescription programs may also help foster a dialogue during clinical visits and improve provider-patient communication [55]. While studies point to a number of positive outcomes of information prescription projects, with a rare exception [36], they do not assess changes in patients' knowledge, health behaviors and outcomes. Factors limiting success of information prescription programs involve low levels of clinicians' buy-in or patients' trust in librarians' expertise. For example, Leisey [38] describes a patient who preferred to receive information from her doctor directly, without librarians' mediation. In addition, patients' high initial levels of health literacy and knowledge may limit effectiveness of information prescription [36,47]. 


\section{Providing health information relevant to disasters and emergencies}

While disaster preparedness and emergency response has long been an established field, librarians' involvement in it is a relatively recent development. This development came with the realization that libraries and librarians have a lot to offer when it comes to providing support to professionals and the general public. Disaster-related information needs of professionals and lay people vary according to the type and phase of the event. For example, information needs during the preparedness phase differ from those during the acute response phase in the immediate aftermath of a disaster. Similarly, information needs in response to a flood or an earthquake differ from those that pertain to a public health epidemic. Yet, as the goal is always to minimize the impact on human life and well-being, health information is usually a prominent component of disaster information.

In the U.S., the period between 2001 and 2005 was marked by disasters of the magnitude that brought disaster preparedness and response to the top of the national agenda. The way libraries responded to these disasters, particularly the Gulf hurricanes, including the 2005 Hurricane Katrina, brought realization of their significant potential in providing support to the public and response agencies. As known, trusted, always welcoming community centers, libraries were natural physical places to which displaced residents gravitated. In the wake of Katrina, Louisiana libraries stepped up to the task by providing the public with shelter, phone charging stations, and Internet connectivity [62]. Librarians held children's programs, distributed water, and provided emotional support to evacuees. In addition to providing general relief, they also used their professional information provision skills. Librarians assisted evacuees with information-literacy-related tasks, such as completing FEMA assistance forms and job applications, creating email accounts necessary for applying for assistance, and using databases to search for friends and family [7]. In addition, librarians provided information for emergency responders, including medical professionals. In recognition of their role, in 2010 FEMA designated public libraries as essential disaster response organizations, thus making them eligible for temporary relocation funding during disasters [62]. Two years later, public libraries of New York and New Jersey played a similar safe haven and support role when Hurricane Sandy struck the East Coast in October 2012 [53].

Growing recognition of the value of librarians' skillset to disaster preparedness and response led to a number of initiatives. In 2008 NLM established the Disaster Information Management Research Center and implemented a Disaster Information Specialist Program, which offers special training courses and information resources [26]. The program, as well as other efforts emerging throughout the country, led to increased librarians' participation in emergency preparedness teams at different levels, from hospitals to cities and counties. While the primary emphasis involves supporting professionals, some efforts also aim to support the public's information needs with regard to different kinds of disasters, including extreme weather events and public health epidemics. One example of such effort is an NN/LM sponsored collaboration between the University of Miami Miller School of Medicine Louis Calder Memorial Library and Miami-Dade County Public Library in South Florida [51]. The area where the libraries are located is home to a medically underserved diverse population; it is also characterized by frequent hurricane threats. In order to conduct health information outreach, librarians from the two libraries organized community fairs, raising emergency preparedness awareness and distributing preparedness resources, as well as more generalized consumer health resources. As part of the collaboration, public librarians used their community connections to promote the fairs, while medical librarians prepared information items. As the aftermath of hurricanes comes with a slew of environmental health concerns, from water pollution to mold growth in homes, Miami-Dade librarians promoted a number of NLM environmental health resources, such as Tox Town, a site addressing environmental health concerns in everyday places. 
While librarians' engagement with disaster health information is gaining momentum, response to events with complex causes and courses may seem more professionally challenging for public librarians. One area of the public's concern and need for reliable health information involves epidemics of infectious diseases (e.g., the 2002-2003 SARS outbreak, the 2009 H1N1 infections). In an article about Ontario public libraries' response to SARS information inquiries, Harris et al. [28] suggest that many public library staff may be unprepared to provide such information. Similarly, in a review of public libraries' responses to the 2009 H1N1 epidemic, Zach [71] notes that about a month after the first case of H1N1 was diagnosed in the U.S., only 15 out of 50 public library systems in the most populated U.S. cities linked to CDC or other e-government information about H1N1. Overall, Zach [71] concluded that, despite some notable efforts, issuing risk alerts and providing epidemics preparedness information was not a priority for public libraries. On the other hand, while comfort level with specialized information provision will always differ by setting and topic, there are also responses of active engagement. According to the same author, some libraries not only linked to e-government information about H1N1, but also posted risk alerts and related messages via their social media channels.

\section{Conclusion}

Libraries have been involved in efforts to improve general literacy, information literacy, health education, and patient education for well over a century. During the past two decades, libraries and librarians have increased their focus on improving the public's access to high quality health information, expanded their participation in research and interventions designed to address variations in health literacy, and produced related training programs and evaluation tools that are relevant to broader audiences. This increased activity is due in part to the development of consumer health information services by the NLM and to training and outreach programs sponsored by NLM via the NN/LM and via partnerships with minority serving educational institutions and community based organizations.

Ensuring that the public has ready access to accurate and understandable health information and that health care institutions and public health agencies make themselves understood to those they serve are never-ending challenges. People are always confronting new personal health issues, new interactions with the health care system, and new imperatives to understand environmental factors affecting community health. Advances in information technology and changes in user preferences are continually affecting the ways in which people seek and obtain understandable health information, interact with health care providers, and engage in community efforts designed to promote health.

Libraries and librarians can be effective partners in conducting research in health literacy and in building sustainable health literacy programs within organizations and communities. Libraries are natural participants and important resources for community-wide health promotion interventions [57, e.g.,] that aim to present their message via multiple channels in multiple formats and different locations throughout a community. With regard to research, librarians are well-positioned to conduct investigations into how patrons and members of the public select and evaluate health information resources and integrate information from multiple sources. They can also contribute to bridging research and practice by conducting systematic evaluations of their health information outreach projects and determining what factors enable or hinder their success [65]. Finally, when it comes to research, librarians can apply their expertise in comprehensive literature searches to conducting meta-analyses of the literature on the connection between health information literacy and behavior.

Although their capabilities will vary, librarians are likely to have knowledge and experience in locating and assessing the quality of health information; networks of contacts and relationships that span 
organizational divisions, disciplines, and stakeholders; and access to unique, although usually modest, sources of external funding. Involving libraries in community-wide health literacy programs can take advantage of their position as shared organizational and community resources, while simultaneously increasing their value to their organizations and their communities.

\section{Acknowledgements}

Work on this paper was supported by the intramural program of the National Library of Medicine, National Institutes of Health.

\section{References}

[1] http://www.mlanet.org/p/cm/ld/fid=42, Retrieved October 17, 2016.

[2] http://www.ala.org/acrl/, Retrieved October 17, 2016.

[3] http://learn.webjunction.org/course/search.php?search=health, Retrieved October 17, 2016.

[4] http://www.virtualability.org/virtual-world-locations/, Retrieved October 17, 2016.

[5] http://www.webjunction.org/news/webjunction/no-wrong-door-at-waukegan-public-library.html, Retrieved October 17, 2016.

[6] https://americanlibrariesmagazine.org/2013/12/03/studying-up-on-health-care-literacy/, Retrieved October 17, 2016.

[7] A. Albanese, L. Blumenstein, N. Oder and M. Rogers, Libraries damaged, librarians respond, after hurricane's fury, Library Journal. 130(15) (2005), 16-17, http://lj.libraryjournal.com/2005/09/ljarchives/libraries-damaged-librariansrespond-after-hurricanes-fury/.

[8] American Library Association, Health information 101. Chicago: American Library Association. https://web.archive.org/ web/20151016072548/http://www.ala.org/rusa/development/healthinfo, 2015. Retrieved October 17, 2016.

[9] C. Arnott Smith and A. Keselman, Consumer health information in public libraries: user needs survey, National Library of Medicine, 2016, in progress.

[10] D.E. Beaudoin, N. Longo, R.A. Logan, J.P. Jones and J.A. Mitchell, Using information prescriptions to refer patients with metabolic conditions to the genetics home reference website, J Med Libr Assoc. 99(1) (2011), 70-76. doi:10.3163/15365050.99.1.012.

[11] M.N. Boulos, L. Hetherington and S. Wheeler, Second life: An overview of the potential of 3-D virtual worlds in medical and health education, Health Info Libr J. 24(4) (2007), 233-245. doi:10.1111/j.1471-1842.2007.00733.x.

[12] V.M. Bowden, F.B. Wood, D.G. Warner, C.A. Olney, E.R. Olivier and E.R. Siegel, Health information Hispanic outreach in the Texas Lower Rio Grande Valley, J Med Libr Assoc. 94(2) (2006), 180-189.

[13] C. Brach, D. Keller, L.M. Hernandez, C. Baur, R. Parker, B. Dreyer et al., Ten attributes of health literate health care organizations, National Academy of Sciences, Washington, 2012, Discussion Paper, https://nam.edu/wp-content/uploads/ 2015/06/BPH_Ten_HLit_Attributes.pdf.

[14] C.M. Burroughs and F.B. Wood, Measuring the difference: guide to planning and evaluating health information outreach, Seattle, WA: National Network of Libraries of Medicine, Pacific Northwest Region, 2000.

[15] N. Calabretta and S.K. Cavanaugh, Education for inpatients: Working with nurses through the clinical information system, Med Ref Serv $Q$ 23(2) (2004), 73-79. doi:10.1300/J115v23n02_07.

[16] A. Chu, J. Huber, B. Mastel-Smith and S. Cesario, "Partnering with seniors for better health": Computer use and Internet health information retrieval among older adults in a low socioeconomic community, J Med Libr Assoc. 97 (2009), 12-20. doi:10.3163/1536-5050.97.1.003.

[17] S. Clifton, P. Jo and S. Jackson, Incorporating Wiis into health information outreach activities, J Hosp Libr. 12(3) (2012), 258-265. doi:10.1080/15323269.2012.692270.

[18] E. Coberly, S.A. Boren, J.W. Davis, A.L. McConnell, R. Chitima-Matsiga, B. Ge et al., Linking clinic patients to Internetbased, condition-specific information prescriptions, J Med Libr Assoc. 98(2) (2010), 160-164. doi:10.3163/1536-5050. 98.2.009.

[19] L.N. Collins, Healthy libraries develop healthy communities: Public libraries and their tremendous efforts to support the affordable care act, J Consum Health Internet. 19(1) (2015), 68-76. doi:10.1080/15398285.2014.988467.

[20] I.D. Cooper and J.A. Crum, New activities and changing roles of health sciences librarians: A systematic review 19902012, J Med Libr Assoc. 101(4) (2013), 268-277. doi:10.3163/1536-5050.101.4.008.

[21] D.M. D'Alessandro, C.D. Kreiter, S.L. Kinzer and M.W. Peterson, A randomized controlled trial of an information prescription for pediatric patient education on the Internet, Arch Pediatr Adolesc Med 158(9) (2004), 857-862. doi:10.1001/ archpedi.158.9.857. 
[22] N. Dancy-Scott, M.L. Rockoff, G.A. Dutcher, A. Keselman, R. Schnall, E.R. Siegel and S. Bakken, Empowering patients and community online: Evaluation of the AIDS community information outreach program, Inf Serv Use. 34(1/2) (2014), 109-148. doi:10.3233/ISU-140720.

[23] B. Dervin, Libraries reaching out with health information to vulnerable populations: Guidance from research on information seeking and use, J Med Libr Assoc. 93(4 Suppl) (2005), S74-S80.

[24] F.P. Donnelly, The geographic distribution of United States public libraries: An analysis of locations and service areas, J Libr Inf Sci. 46(22) (2014), 110-129. doi:10.1177/09610006124702762.

[25] D. Eakin, S.J. Jackson and G.G. Hannigan, Consumer health information: Libraries as partners, Bull Med Libr Assoc. 68(2) (1980), 220-229.

[26] R.M. Featherstone, B.J. Lyon and A.B. Ruffin, Library roles in disaster response: An oral history project by the National Library of Medicine, J Med Libr Assoc. 96(4) (2008), 343-350. doi:10.3163/1536-5050.96.4.009.

[27] F. Goldsmith, Libraries and the Affordable Care Act: Helping the community understand health-care options, Chicago, IL, ALA, 2015, $112 \mathrm{p}$.

[28] R. Harris, C.N. Wathen and D. Chan, Public library responses to a consumer health inquiry in a public health crisis, Ref User Serv Q 45(2) (2005), 146-154.

[29] T. Henner, An intergenerational approach to Internet training: Student-led outreach to promote seniors' use of Internet health resources, J Consum Health Internet. 13(4) (2009), 334-346. doi:10.1080/15398280903340822.

[30] K.E. Hessler, Health literacy and law: Empowering libraries to improve access to consumer health information and ACA compliance, Serials Librarian 69(3/4) (2015), 334-346. doi:10.1080/0361526X.2015.1105767.

[31] Institute of Medicine of the National Academies, Committee on Health Literacy, L. Nielsen-Bohlman, A.M. Panzer and D.A. Kindig (eds), Health Literacy: A Prescription to End Confusion, National Academies Press, Washington, 2004.

[32] S. Jones and J. Shipman, Health information retrieval project: Librarians and physicians collaborate to empower patients with quality health information, Va Lib. 50(2) (2004), 11-16.

[33] S.D. Jones, "Information Rx" project launched in Virginia, Nat Netw. 29(3) (2005), 20-21.

[34] M. Kars, L.M. Baker and F.L. Wilson (eds), The Medical Library Association Guide to Health Literacy, Neal-Schuman Publishers, New York, 2008, 314 p.

[35] K. Kohn, Taking our pulse: Reactions to ACA from Illinois libraries, ILA Reporter 31(6) (2013), 8-11. https://www.ila. org/content/documents/Reporter_1213.pdf, Retrieved October 17, 2016.

[36] T.Y. Koonce, N.B. Giuse, S.V. Kusnoor, S. Hurley and F. Ye, A personalized approach to deliver health care information to diabetic patients in community care clinics, J Med Libr Assoc. 103(3) (2015), 123-130. doi:10.3163/1536-5050.103.3. 004.

[37] T.Y. Koonce, N.B. Giuse and A.B. Storrow, A pilot study to evaluate learning style-tailored information prescriptions for hypertensive emergency department patients, J Med Libr Assoc. 99(4) (2011), 280-289. doi:10.3163/1536-5050.99.4. 005 .

[38] M. Leisey, The journey project: A case study in providing health information to mitigate health disparities, J Med Libr Assoc. 97(1) (2009), 30-33. doi:10.3163/1536-5050.97.1.005.

[39] D.A. Lindberg and B.L. Humphreys, A time of change for medical informatics in the USA, Yearb Med Inform. 1 (1999), 53-57.

[40] K.L. Lindner and L. Sabbagh, In a new element: Medical librarians making patient education rounds, J Med Libr Assoc. 92(1) (2004), 94-97.

[41] M. Malachowski, Obamacare and the proper role of public libraries in health literacy, Computers in Libraries. 34(1) (2014), 4-9, http://pqasb.pqarchiver.com/infotoday/doc/1496060324.html.

[42] M. McKnight, Information prescriptions, 1930-2013: An international history and comprehensive review, J Med Libr Assoc. 102(4) (2014), 271-280. doi:10.3163/1536-5050.102.4.008.

[43] Medical Library Association, Health Information Literacy Curriculum-Toolkit Cover Ideas, Medical Library Association, Chicago, 2016. http://www.mlanet.org/p/do/sd/sid=461. Retrieved October 17, 2016.

[44] N. Miller, E.M. Lacroix and J.E. Backus, MEDLINEplus: Building and maintaining the National Library of Medicine's consumer health web service, Bull Med Libr Assoc. 88(1) (2000), 11-17.

[45] National Library of Medicine (US), Board of Regents, National Library of Medicine long range plan, 2000-2005/report of the Board of Regents, National Library of Medicine, Bethesda, MD, 2000, 39 p.

[46] National Library of Medicine (US), Board of Regents, Charting the course for the 21st century: NLM's long range plan 2006-2016/NLM Board of Regents. NIH publication no.: 07-4890. US Department of Health and Human Services, Public Health Service, National Institutes of Health, National Library of Medicine, Bethesda, MD, 2006, 66 p. https://collections. nlm.nih.gov/ext/kirtasbse/101290062/PDF/101290062.pdf.

[47] K.B. Oliver, H.P. Lehmann, A.C. Wolff, L.W. Davidson, P.K. Donohue, M.M. Gilmore et al., Evaluating information prescriptions in two clinical environments, J Med Libr Assoc. 99(3) (2011), 237-246. doi:10.3163/1536-5050.99.3.011. 
[48] C.A. Olney, L. Hansen, A. Vickman, S. Reibman, F.B. Wood and E. Siegel, Long-term outcomes of the ;VIVA! Peer Tutor project: Use of MedlinePlus by former peer tutors and the adults they taught, J Med Libr Assoc. 99(4) (2011), 317-320. doi:10.3163/1536-5050.99.4.012.

[49] C.A. Olney, D.G. Warner, G. Reyna, F.B. Wood and E.R. Siegel, MedlinePlus and the challenge of low health literacy: Findings from the colonias project, J Med Libr Assoc. 95(1) (2007), 31-39.

[50] S. Pati, J.E. Kavanagh, S.K. Bhatt, A.T. Wong, K. Noonan and A. Cnaan, Reading level of medicaid renewal applications, Acad Pediatr. 12(4) (2012), 297-301. doi:10.1016/j.acap.2012.04.008.

[51] G. Paulaitis, E. Vardell and J. Shipley, Collaborating with public librarians to promote emergency preparedness and safety awareness, J Consum Health Internet. 15(4) (2011), 313-321. doi:10.1080/15398285.2011.623556.

[52] S.C. Ratzan and R.M. Parker, Introduction, in: Health Literacy. Current Bibliographies in Medicine No. 2000-1, C.R. Selden, M. Zorn, S.C. Ratzan and R.M. Parker, eds, National Library of Medicine, National Institutes of Health, U.S. Department of Health and Human Services, Bethesda, MD, 2000. https://www.nlm.nih.gov/archive/20061214/pubs/cbm/ hliteracy.pdf.

[53] J. Rose, For disaster preparedness: Pack a library card? Morning Edition on National Public Radio, 2013, http://www.npr. org/2013/08/12/210541233/for-disasters-pack-a-first-aid-kit-bottled-water-and-a-library-card, Retrieved October 17, 2016.

[54] C.R. Selden, M. Zorn, S.C. Ratzan and R.M. Parker (eds), Current Bibliographies in Medicine No. 2000-1-Health Literacy, National Library of Medicine, National Institutes of Health, U.S. Department of Health and Human Services, Bethesda, MD, 2000, 33 p. https://www.nlm.nih.gov/archive/20061214/pubs/cbm/hliteracy.pdf.

[55] E.R. Siegel, R.A. Logan, R.L. Harnsberger, K. Cravedi, J.A. Krause, B. Lyon et al., Information Rx: Evaluation of a new informatics tool for physicians, patients, and libraries, Inf Serv Use. 26(1) (2006), 1-10.

[56] C.A. Smith, "The easier-to-use version": Public librarian awareness of consumer health resources from the National Library of Medicine, J Consum Health Internet. 15(2) (2011), 149-163. doi:10.1080/15398285.2011.573339.

[57] M. Smith, K.F. Mateo, H. Morita, C. Hutchinson and A.T. Cohall, Effectiveness of a multifaceted community-based promotion strategy on use of GetHealthyHarlem.org, a local community health education website, Health Promot Pract. 16(4) (2015), 480-491. doi:10.1177/1524839915571632.

[58] M. Snyder, J.T. Huber and D. Wegmann, Education for consumer health: A train the trainer collaboration, Health Care Internet. 6(4) (2002), 49-62. doi:10.1300/J138v06n04_05.

[59] M.L. Strong, L. Guillot and B.J. Senior, CHAT: A model for health literacy instruction, New Libr World. 113(5/6) (2012), 249-261. doi:10.1108/03074801211226337.

[60] S.M. Swanberg, C.C. Dennison, A. Farrell, V. Machel, C. Marton, K.K. O'Brien et al., Instructional methods used by health sciences librarians to teach evidence-based practice (EBP): A systematic review, J Med Libr Assoc. 104(3) (2016), 197-208. doi:10.3163/1536-5050.104.3.004.

[61] E. Vardell, Health insurance literacy: Implications for librarian involvement, in: The Medical Library Association Guide to Answering Questions About the Affordable Care Act, E. Vardell, ed., Rowman \& Littlefield, Lanham, MD, 2015, pp. 23-35.

[62] S. Veil and B. Bishop, Opportunities and challenges for public libraries to enhance community resilience, Risk Analysis. 34(4) (2014), 721-732. doi:10.1111/risa.12130.

[63] D.G. Warner, C.A. Olney, F.B. Wood, L. Hansen and V.M. Bowden, High school peer tutors teach MedlinePlus: A model for Hispanic outreach, J Med Libr Assoc. 93(2) (2005), 243-252.

[64] C.B. Wessel, J.A. Wozar and B.A. Epstein, The role of the academic medical center library in training public librarians, J Med Libr Assoc. 91(3) (2003), 352-360.

[65] W. Whitney, G.A. Dutcher and A. Keselman, Evaluation of health information outreach: Theory, practice, and future, J Med Libr Assoc 101(2) (2013), 138-146. doi:10.3163/1536-5050.101.2.009.

[66] M.D. Williams, K.W. Gish, N.B. Giuse, N.A. Sathe and D.L. Carrell, The Patient Informatics Consult Service (PICS): An approach for a patient-centered service, Bull Med Libr Assoc. 89(2) (2001), 185-193.

[67] F.B. Wood, B. Lyon, M.B. Schell, P. Kitendaugh, V.H. Cid and E.R. Siege, Public library consumer health information pilot project: Results of a National Library of Medicine evaluation, Bull Med Libr Assoc. 88(4) (2000), 314-322.

[68] F.B. Wood, E.R. Siegel, G.A. Dutcher, A. Ruffin, R.A. Logan and J.C. Scott, The National Library of Medicine's Native American outreach portfolio: A descriptive overview, J Med Libr Assoc. 93(4 Suppl) (2005), S21-S34.

[69] D.E. Woodson, D.F. Timm and D. Jones, Teaching kids about healthy lifestyles through stories and games: Partnering with public libraries to reach local children, J Hosp Libr. 11(1) (2011), 59-69. doi:10.1080/15323269.2011.538619.

[70] B. Xie and J.M. Bugg, Public library computer training for older adults to access high-quality Internet health information, Libr Inf Sci Res. 31(3) (2009), 155-162. doi:10.1016/j.lisr.2009.03.004.

[71] L. Zach, What do I do in an emergency? The role of public libraries in providing information during times of crisis, Sci Tech Libr. 30(4) (2011), 404-413. doi:10.1080/0194262X.2011.626341. 